\title{
ATENCIÓN A LA POBLACIÓN EN DESPLAZAMIENTO FORZADO INTERNO EN COLOMBIA
}

Ana Luisa Velandia Mora

N. R., B. N., M. A., Ph. D.

Profesor Emérito. Universidad Nacional de Colombia

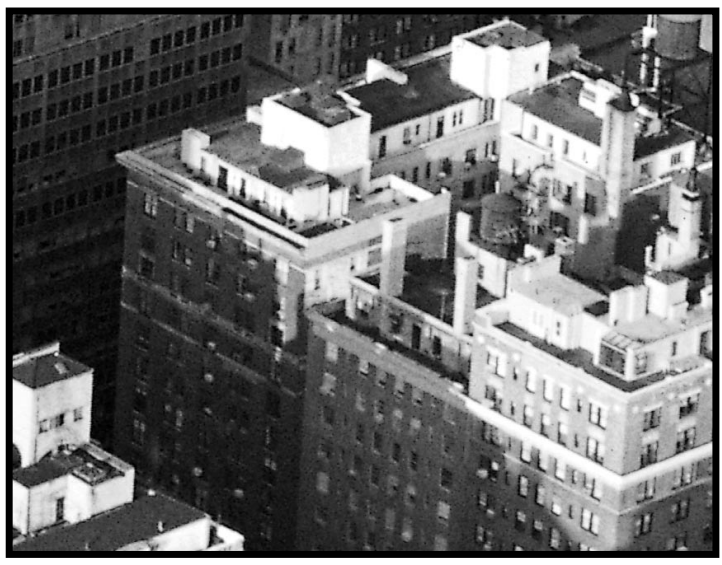

CARE OF THE POPULATION AFFECTED BY FORCED INTERNAL MIGRATION IN COLOMBIA

\section{ABSTRACT}

Considering that in Colombia one of the most vulnerable groups is that of the migrated, the key topic in this article is forced internal migration in Colombia. It is our aim to answer these questions: Who are we talking about? What is happening? Why is happening? What are we doing about it? and What should we be doing?, highlighting factors related to gender and political and economical issues, and eventually analysing the models and approaches used.

Key words: migration, transcultural nursing, Colombia

\section{RESUMEN}

Deniendo en cuenta que en Colombia, uno de los grupos más desfavorecidos son los “des-

1 plazados"; el tema central de este artículo es

el Desplazamiento Forzado Interno en Colombia. Se pretende responder a las siguientes preguntas: ¿De quiénes estamos hablando?, ¿Qué esta suce- diendo?, ¿Por qué está sucediendo?, ¿Qué estamos haciendo?, y ¿Qué deberíamos hacer; llamando la atención sobre los factores relacionados con el género y los aspectos políticos y económicos de este problema; y finalmente, analizando los modelos y abordajes utilizados.

Palabras claves: desplazamiento, enfermería transcultural, Colombia.

\section{¿De quiénes estamos hablando?}

Son seres callados, que un día, una madrugada, tuvieron que salir con sus hijos en los brazos huyendo, dejando atrás todo lo que les pertenecía para poder salvar sus vidas. Por lo general, son personas que han vivido gran parte de su vida en territorios controlados por la insurgencia y los grupos paramilitares, y en donde la presencia del Estado ha sido nula o muy deficiente o estrictamente militar.

Aspectos conceptuales: diferencias entre desplazado, refugiado y asilado.

En primer lugar, hay que tener en cuenta que existen tres grandes tipos de migrantes, en razón de la causa que general el desplazamiento: migrantes por causas socioeconómicas (originados por las condiciones de producción), migrantes por desastres naturales y migrantes por razones políticas.

Dentro de las migraciones políticas tenemos que distinguir tres tipos:

Asilados: en el derecho de gentes, es el amparo que los países o estados ofrecen a los perseguidos políticos para que la autoridad no los pueda procesar o someter a prisión.

Refugiados: aquellas personas que se han visto obligadas a abandonar su país "debido a una agresión externa, ocupación, dominación extranjera o sucesos que alteran gravemente el orden público en una parte o en todo el país de origen o nacionalidad". 
La definición técnica del desplazado es: "toda persona que se ha visto forzada a migrar dentro del territorio nacional abandonando su localidad de residencia o sus actividades económicas habituales, porque su vida, integridad física o libertad han sido vulneradas o se encuentran amenazadas, debido a la existencia de cualquiera de las siguientes situaciones causadas por el hombre: conflicto armado interno, disturbios o tensiones interiores, violencia generalizada, violaciones masivas de los derechos humanos y otras circunstancias emanadas de las situaciones anteriores que puedan adulterar o alteren drásticamente el orden público". (Tomado de la página: www.desplazados.org.co)

\section{¿Qué esta sucediendo?}

Caracterización del problema:

El 70\% de la población es menor de 19 años. La edad de las personas desplazadas en el $31.67 \%$ corresponde a niños menores de 10 años. (Tomado de ReliefWeb: Colombia: Desplazados: Rostros Anónimos de la guerra. Por Jorge Rojas)

El Secretariado Nacional de Pastoral Social (Tomado de: http://pagina.de/desplazados), de Diciembre de 2003 reporta que los principales departamentos expulsores fueron en su orden: Bolivar, Antioquia, Meta, Tolima y Chocó; mientras que los principales departamentos receptores fueron a su vez los departamentos de Bolívar, Meta, Antioquia, Valle y Nariño.

Con referencia a las Etnias de procedencia, del total de familias registradas, el $12 \%$ pertenece a afrodescendientes, $2 \%$ a población indígena y $86 \%$ pertenece a la raza mestiza o blanca. En cuanto a la Tenencia de la tierra, las familias de desplazados en Colombia declaran haber abandonado propiedades que ascienden a 569, 54 hectáreas.

El $50 \%$ de las familias de desplazados en el territorio nacional no forma parte de ningún tipo de organización, el $13 \%$ pertenece a organizaciones campesinas, mientras que el $5 \%$ pertenece a organizaciones comunitarias o de otro tipo. Sólo el $1 \%$ forma parte de organizaciones de mujeres. El $61.10 \%$ de los jefes cabeza de familia son hombres, y el $38.90 \%$ son mujeres; de las cuales $65 \%$ son mujeres solas, bien sea separadas, viudas o solteras. El tamaño promedio de las familias desplazadas es de 5.09 personas. Al analizar estadística- mente la distribución por edad y género se observan diferencias significativas, lo cual demuestra la necesidad de formular políticas de acción por género y rango de edad.

Respecto a Escolaridad, al analizar la situación antes y después del desplazamiento, se observa que se redujo en un $32 \%$ en el caso de los hombres, mientras que en el caso de las mujeres esta tasa disminuyó en un 34\%.

Entre las personas en situación de desplazamiento, el $3.76 \%$ sufre algún tipo de discapacidad (ceguera, retraso mental, sordera, parálisis, mudez). Por otra parte, se presentan los efectos de salud mental que trae consigo el desplazamiento forzado, representados en molestias respiratorias, dolor de cabeza, digestivas, cardiovasculares y de piel.

En lo que respecta a Aspectos Laborales, el aspecto más importante es que la dedicación en actividades relacionadas con la agricultura, disminuye. Situación similar se observa en el trabajo que realizaban las mujeres en su hogar. Lo anterior contrasta con las actividades relacionadas con oficios varios y otros trabajos, los cuales muestran un incremento, así como la vinculación a actividades relacionadas con la economía no formal. En términos concretos, esto significa que han tenido que dedicarse a otros oficios no discriminados. Esta situación puede ser explicada porque el desplazamiento disminuye la posibilidad de seguridad alimentaria en las familias, lo cual obliga a hombres y mujeres a buscar fuentes de ingreso alternativas.

\section{¿Por qué está sucediendo?}

La crisis estructural del campo, los modelos de desarrollo aperturistas y, por supuesto la violencia, se han encargado de generar un inmenso flujo migratorio en el que se confunden desplazados, migrantes, trabajadores temporales, colonos, trabajadores de cultivos de uso ilícito y, más recientemente, pueblos indígenas y comunidades negras desarraigados de su entorno socio-económico y cultural en medio de traumáticos ciclos de expulsión y reasentamiento que ponen en peligro su propia existencia. (Tomado de ReliefWeb: Colombia: Desplazados: Rostros Anónimos de la guerra. Por Jorge Rojas)

El conflicto armado es la causa del $90 \%$ del total de desplazamientos, que se producen de 
manera individual y familiar en un $62 \%$ y colectivamente, a manera de éxodo en un $35 \%$. La mayoría (el 66\%) provienen del campo o de zonas de alta influencia rural y son mujeres cabeza de familia el $22 \%$, en tanto que el $57 \%$ del total de la población desplazada corresponde al sexo femenino.

Las partes en conflicto incurren en reiteradas violaciones a las leyes de la guerra: las fuerzas armadas en operaciones de contrainsurgencia bombardean y ametrallan indiscriminadamente los campos colombianos y zonas que consideran de influencia guerrillera, realizan ataques desproporcionados y las "operaciones rastrillo" queman viviendas y cultivos, retienen alimentos, registran a la población, impiden la libre movilización y presionan a la población a colaborar con las acciones militares. Las organizaciones insurgentes cometen acciones que perjudican gravemente a la población civil: atentados dinamiteros contra bienes civiles e infraestructura energética, minado de campos, secuestros y ejecuciones. (Tomado de la página: www.desplazados.org.co) Por ejemplo, las comunidades aborígenes de Egorókera, Baquiaza y Playita, en el Opogadó, y Hoja Blanca y Unión Cuití en el Cuía y el Napipi, se encuentran en un corredor por el cual los grupos armados ilegales patrullan la orilla occidental del Atrato medio y bajo. (Revista Semana, Edición 1162).

Los Paramilitares son señalados como presuntos responsables por el $43 \%$ de la población desplazada, la Guerrilla por el 35\%, las Fuerzas Militares del Estado por el $6 \%$ y desconocidos por el $15 \%$. Las amenazas, el miedo, las masacres, los asesinatos y las desapariciones, son los principales hechos que generaron el desplazamiento. Los Grupos Paramilitares presentan los mayores índices de crueldad en sus acciones contra la población civil. La Guerrilla aumentó significativamente su presunta responsabilidad como consecuencia del reclutamiento forzado en sus zonas de influencia. (Tomado de ReliefWeb: Colombia: Desplazados: Rostros Anónimos de la guerra. Por Jorge Rojas)

\section{¿Qué estamos haciendo?}

La Cooperación Técnica de la Organización Panamericana de la Salud-OPS en el Departamento de Antioquia en el Bienio
2002-2003, incluyó las siguientes actividades relacionadas con población desplazada: 1) se culminó el estudio del Perfil Epidemiológico de la población desplazada y la población vulnerable estrato socioeconómico 1 en la ciudad de Medellín; 2) se recopila la información situacional del Comportamiento del desplazamiento en el Departamento de Antioquia, por municipio y por subregión y se mantiene graficación y mapeo con actualización permanente; 3) culminación de la investigación sobre Sistematización de experiencias de atención psicosocial en Antioquia, realizada con base en las actividades desarrolladas en los municipios afectados por el conflicto armado y población desplazada 1999-2003; 4) contribución para la puesta en marcha de un Modelo de Atención Primaria en Salud, para población vulnerable y desplazada; 5) realización de encuentros interinstitucionales para el Mejoramiento de la atención en salud a la población desplazada por la violencia; 6) fortalecimiento de los Comités de atención a población desplazada por la violencia; y finalmente, cooperación técnica para la elaboración del Proyecto para la reducción de la vulnerabilidad del personal sanitario en funciones de misión médica ante las infracciones en Antioquia, en el marco del conflicto armado. (Tomado de: http://pagina.de/desplazados).

El Secretariado Nacional de Pastoral Social (Tomado de: http://pagina.de/desplazados), de Diciembre de 2003, informa que las familias de desplazados han recibido ayuda representada básicamente en alimentos y alojamiento, y en menor grado en atención de salud, medicinas, colchonetas y elementos de aseo. También han recibido ayuda representada en pago de arrendamiento de vivienda, hamacas, cobijas, sábanas, toallas, kits escolares y capacitación. La ayuda a las familias desplazadas se ha hecho a nivel nacional, a través de Pastoral Social, la Cruz Roja Colombiana y las Secretarías de Salud, y en menor grado a nivel internacional.

\section{Atención en Salud}

En la ciudad capital del país, Investigadores procedentes de la Universidad del Rosario en Colombia, la Universidad Autónoma de Barcelona, al CHC Consultoria i Gestió, S. A. de 
Barcelona y el Hospital Josep Trueta de Girona, de España; realizaron un estudio sobre las Necesidades en Salud de la Población Desplazada por Conflicto Armado en Bogotá. (Tomado de Internet: Rev Esp Salud Pública 2003; 77: 257-266).

En relación a los problemas originados por el desplazamiento, las personas entrevistadas refieren en primer lugar compromiso de la salud mental y alteraciones psicosociales, seguido de los relativos a cambios en la alimentación y, en menor grado, dolores, problemas gastrointestinales y respiratorios. La salud mental no sólo parece estar comprometida como consecuencia de haber vivido el conflicto bélico, sino también por el rechazo y la estigmatización que su nueva condición social genera sobre los desplazados. Se constituye así en uno de los problemas más importantes que padece la población desplazada.

En relación con el acceso a los servicios de salud, el colectivo estudiado percibe situaciones de exclusión y marginación. La precariedad en sus ingresos no sólo condiciona el acceso a los servicios de salud y a los tratamientos prescritos, sino también a una vivienda adecuada y a una alimentación balanceada que cubra los requerimientos nutricionales de la familia. Las dificultades para adquirir una alimentación cuya calidad y cantidad les permita un adecuado balance nutricional es otro problema manifestado por los entrevistados y ya puesto de manifiesto por numerosos estudios en población desplazada.

Las necesidades de atención a la salud descritas por los entrevistados se corresponden con los problemas percibidos: acceso a los servicios de salud y la atención en áreas específicas, como el apoyo psicológico y el soporte nutricional. En este estudio se destaca el apoyo psicológico como una de las principales necesidades de atención, dada la problemática de salud mental que tiene esta población y su propia percepción del problema.

La complejidad de las causas subyacentes a los problemas de salud de las personas desplazadas, dicen los autores, señala la necesidad de una amplia política intersectorial que permita la reubicación o el retorno del sujeto y su familia, en condiciones adecuadas, como requisito fundamental para el logro del desarrollo humano.
Algunos autores analizan críticamente el papel del Estado en las políticas y programas de salud para los desplazados, los cuales "carecen de programas integrales y de modelos de promoción, prevención y de salud pública. Hasta ahora los programas de salud dirigidos a la población desplazada están orientados a atender las alteraciones físicas de los individuos desplazados". (García Vargas, 2003).

\section{¿Qué deberíamos hacer?}

Las familias tienen gran cantidad de necesidades urgentes especialmente en aspectos relacionados con alimentación, alojamiento, colchonetas, elementos de aseo y de cocina, vestuario y atención en salud; las cuales se relacionan con necesidades en aspectos de trabajo, educación, apoyo psicosocial y asesoría jurídica, entre otros.

El $61 \%$ de las familias de desplazados aspiran a permanecer en el lugar donde se encuentran ubicadas en la actualidad, mientras que el $23 \%$ desea reubicarse en otro lugar y el $15 \%$ desea regresar a su lugar de origen. Un porcentaje muy bajo aspira a salir del país. (Tomado de: http://pagina.de/desplazados)

\section{Modelos o enfoques de abordaje}

Básicamente hay dos enfoques de la política de atención al desplazamiento: el enfoque de protección y reparación de derechos, versus, el enfoque de asistencia social.

Para el análisis de este tema es necesario hacer antes algunas precisiones relativas a los derechos

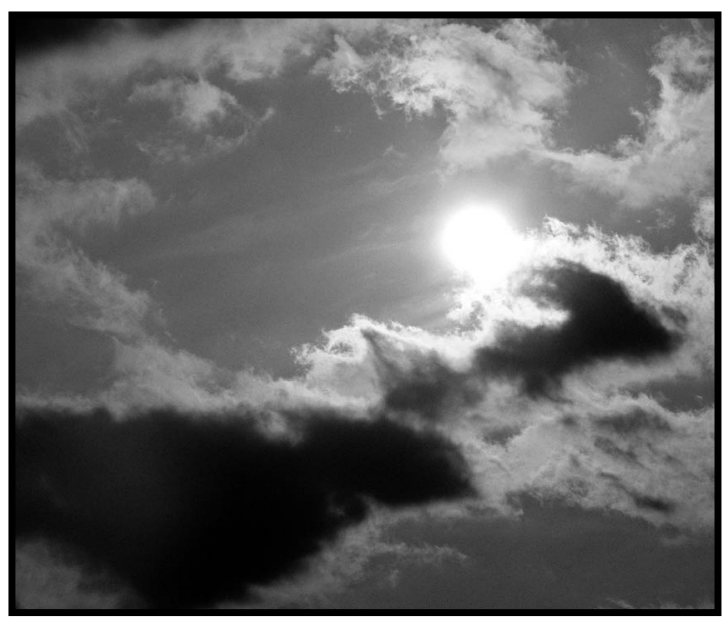


de la PID - Población Internamente Desplazada, dado que existen diferentes categorías de los mismos y por lo tanto, los criterios de evaluación de las respuestas, son también diferentes.

En primer lugar debe señalarse que existen unos derechos que se consideran fundamentales, primarios, básicos y cuya protección y reparación exige respuestas urgentes del Estado; éstos son tales como el derecho a la vida y a la integridad, a la seguridad, etc. Estas respuestas deben garantizar el castigo a los culpables así como evitar la repetición de tales hechos. En segundo lugar, están los derechos sociales y económicos de la PID, los cuales son progresivos y deben ser satisfechos a través de la política social. En tercer lugar, existen otros derechos políticos, culturales, etc. de la PID; por ejemplo a la integración social y al pleno ejercicio de sus derechos ciudadanos; cuyo reconocimiento y satisfacción se realiza en el campo de la construcción y desarrollo del capital social, que va más allá de la atención en cuanto a educación, salud, vivienda, empleo, etc.

\section{Comentarios finales:}

El gobierno colombiano considera que el enfoque adoptado en sus políticas busca: a) enfrentar las causas estructurales del desplazamiento, b) trascender el tradicional enfoque asistencialista y puramente de emergencia, c) fortalecer las capacidades de las comunidades afectadas, d) abordar el diseño y la ejecución de las acciones bajo un enfoque poblacional y territorial consistente con la heterogeneidad del fenómeno del desplazamiento forzado, y e) involucrar a la sociedad civil y al sector privado en la ejecución de las acciones. (Documento del Consejo de Política Económica y Social-CONPES, citado en la página www.acnur. org/biblioteca/pdf/

Sin embargo, el mismo Balance de la Política de Atención al Desplazamiento Interno Forzado en Colombia, concluye que "aunque existen normas jurídicas y jurisprudencia que refrendan el enfoque de reconocimiento de derechos y el carácter humanitario de la respuesta que debe dar el Estado a la población afectada por el desplazamiento forzado que queda en condición de vulnerabilidad, la gran mayoría de desarrollos instrumentales de la política, todavía están concebidos y diseñados bajo un paradigma de mera asistencia social regular a gru- pos vulnerables y para operar en circunstancias de normalidad, de modo que no permiten a las entidades estatales responder de manera ágil, efectiva y oportuna a la PID (Población Internamente Desplazada), en medio de un conflicto armado que además es creciente." En el fondo de todo lo anterior, subyace en la política una tensión entre un enfoque de derechos y una concepción de asistencia social convencional a población vulnerable.

El argumento de fondo ha sido planteado por la Defensoría del Pueblo y consiste en que: "El desplazamiento forzado es consecuencia de la falla en el deber de protección por parte del Estado. Así el causante directo del desplazamiento no sea un agente del Estado, este no puede sustraerse de su obligación de respetar, proteger y garantizar los derechos de la población desplazada..."

Es importante hacer notar que "La persona desplazada, además del derecho a ser atendida por el Estado, tiene derecho a: (i) conocer la verdad acerca de quien fue el causante del desplazamiento; (ii) a la justicia, para que el desplazamiento como delito que es, no quede en la impunidad; y (iii) a la reparación de los daños sufridos." (Tomado de: www.acnur.org/biblioteca/pdf/1912.pdf).

En salud se hace aún más evidente, el conflicto entre las formas de abordaje del problema: atendemos los problemas de la salud de la población desplazada de manera convencional; atendemos a ésta población con el carácter de "emergencia"; o enfrentamos las causas estructurales del desplazamiento, fortaleciendo las capacidades de las comunidades afectadas.

\section{Fuentes de referencia:}

- www.desplazados.org.co

- ReliefWeb: Colombia: Desplazados: Rostros Anónimos de la guerra. Por Jorge Rojas

- www.acnur.org/biblioteca/pdf/

- http://pagina.de/desplazados

- acnur.org/biblioteca/pdf/1912-1922.pdf

- acnur.org/biblioteca/pdf/2243.pdf

- Rev Esp Salud Pública 2003; 77: 257 - 266

- www.codhes.org.co

- García Vargas, Mery Constanza. "Desplazamiento e Impactos en la Salud". Revista Avances en Enfermería, Bogotá, Junio 2003, XXI (1): 15 - 23.

- Revista Semana Colombia. "La Soledad Embera". Bogotá, Agosto 9 a 16 de 2004, Edición No. 1162, págs. $50-52$. 